\title{
Xeroderma Pigmentosum and Bone Marrow Aplasia: A Rare Association
}

\begin{abstract}
Xeroderma pigmentosum (XP) is a rare autosomal recessive disorder characterized by hypersensitivity to ultraviolet rays and predisposition to cutaneous malignancies. Hematological disorders associated with XP include myelodysplastic syndrome and acute leukemia. We report a 7-year-old child with $\mathrm{XP}$ along with squamous cell carcinoma and bone marrow aplasia.
\end{abstract}

Keywords: Aplastic anemia, pancytopenia, squamous cell carcinoma, xeroderma pigmentosum

\section{Introduction}

Xeroderma pigmentosum (XP) is a rare inherited autosomal recessive disorder characterized by extreme hypersensitivity to ultraviolet rays predisposing to early cutaneous malignancies. Other abnormalities include neurological and ocular diseases. ${ }^{[1,2]}$

The incidence of XP varies across geographic areas, one in one hundred thousand in Europe and the US to one in 22,000 in Japan. The incidence in India has not been studied so far but is believed to be less when compared to the Western countries. ${ }^{[2,3]}$

There is no sex predilection. Pathophysiology of this inherited disorder is the defect in the nucleotide excision repair mechanism, and hence, the DNA damage caused by ultraviolet (UV) rays is unrepaired resulting in genomic instability which leads to predisposition to oculo-cutaneous malignancies as well as other internal malignancies. The other manifestations of XP include hyperpigmentation, premature aging, and neurological dysfunction. Photosensitivity and burning sensation after exposure to the sun precede the dryness (xeroderma) and pigmentation of skin and ocular manifestations such as photophobia and keratitis..$^{[4,5]}$

Hematological abnormalities reported include myelodysplastic syndrome, which is characterized by refractory anemia with excess blast cells and leukemias. ${ }^{[6]} \mathrm{A}$ single

This is an open access article distributed under the terms of the Creative Commons Attribution-NonCommercial-ShareAlike 3.0 License, which allows others to remix, tweak, and build upon the work non-commercially, as long as the author is credited and the new creations are licensed under the identical terms.

For reprints contact: reprints@medknow.com case of XP in association with bone marrow failure has also been reported..$^{[7]}$

Bone marrow aplasia in $\mathrm{XP}$ is very rare when compared to its presence in other DNA repair mechanism defects such as Fanconi anemia, Bloom syndrome, and ataxia telangiectasia.

We present here an interesting case of XP associated with bone marrow aplasia.

\section{Case Report}

A 7-year-old male child, a known case of XP, presented with a swelling in the right infraorbital region of short duration associated with pain and discharge from the lesion.

The diagnosis of XP was made based on the clinical findings in the previous admission when the child presented with dermatological symptoms, photosensitivity, itching over the face, and hyperpigmentation. Pigmentation progressed with age. Erythematous scaly plaques with pigmented macules were seen over the areas exposed to the sun. The child was born of a nonconsanguinous marriage and attained normal developmental milestones. There were no neurological manifestations.

In the current admission, complete hemogram showed pancytopenia (white blood cell count $-3.5 \times 10^{3} / \mu 1$, red blood cell count - $1.01 \times 10^{6} / \mu 1$, and platelet count $\left.-21 \times 10^{3} / \mu 1\right)$. Peripheral smear revealed a macrocytic blood picture. There were no atypical cells in the smear [Figure 1].

\footnotetext{
How to cite this article: Shanmugasundaram $\mathrm{S}$, Kumar PN, Lakshmi SV, Chaitra V. Xeroderma pigmentosum and bone marrow aplasia: A rare association. Indian $\mathrm{J}$ Med Paediatr Oncol 2018;39:247-9.
}

Sakthisankari Shanmugasundaram, Prasanna N Kumar, S Vidhya Lakshmi, V Chaitra

Department of Pathology, PSG Institute of Medical Sciences and Research, Coimbatore, Tamil Nadu, India

Address for correspondence: Dr. Sakthisankari Shanmugasundaram, Department of Pathology, PSG Institute of Medical Sciences and Research, Coimbatore - 641 004, Tamil Nadu, India. E-mail: sakthissankari@gmail. com 
Bone marrow aspiration was done. The smears were paucicellular with adipocyte fragments and scant hematopoietic elements. There were no features of dyspoiesis in any lineage [Figure 2].

Bone marrow trephine was markedly hypocellular with fatty marrow and minimal hematopoietic tissue. There was no evidence of an infiltrative disease [Figure 3].

Wide-local excision of the infraorbital swelling showed a moderately differentiated squamous cell carcinoma [Figure 4].

\section{Discussion}

$\mathrm{XP}$ is a rare genodermatosis caused by defects in the normal repair of DNA damaged by exposure to sunlight. There are eight complementation groups of XP (XP-A to G) caused by defective nucleotide excision repair, corresponding to mutations in the genes encoding XPA, XPB, XPC, XPD, $\mathrm{XPE}, \mathrm{XPF}, \mathrm{XPG}$, and XP dominant. The incidence and the age at presentation vary, ranging from early infancy to adulthood. XP has been reported to be common with consanguineous marriages. ${ }^{[8]}$

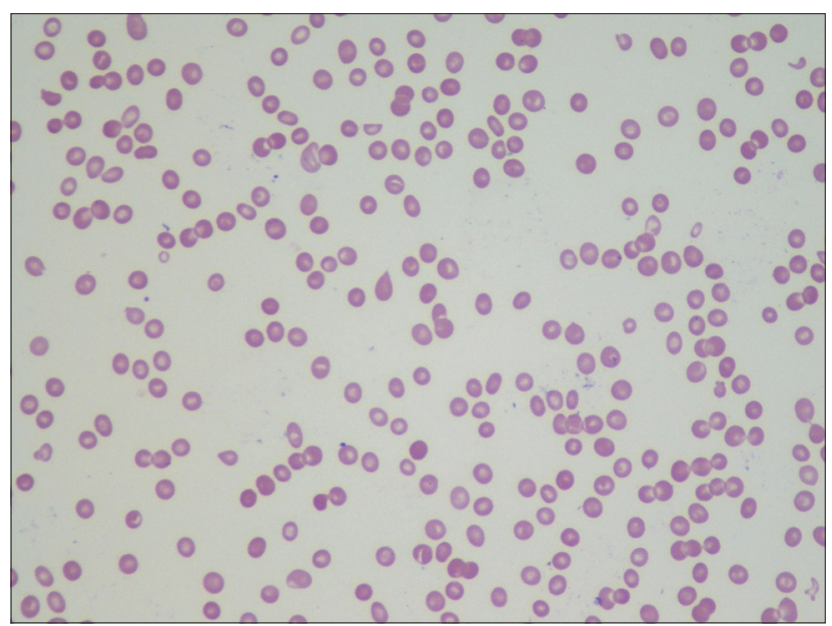

Figure 1: Peripheral smear showing pancytopenia $(\times 40)$

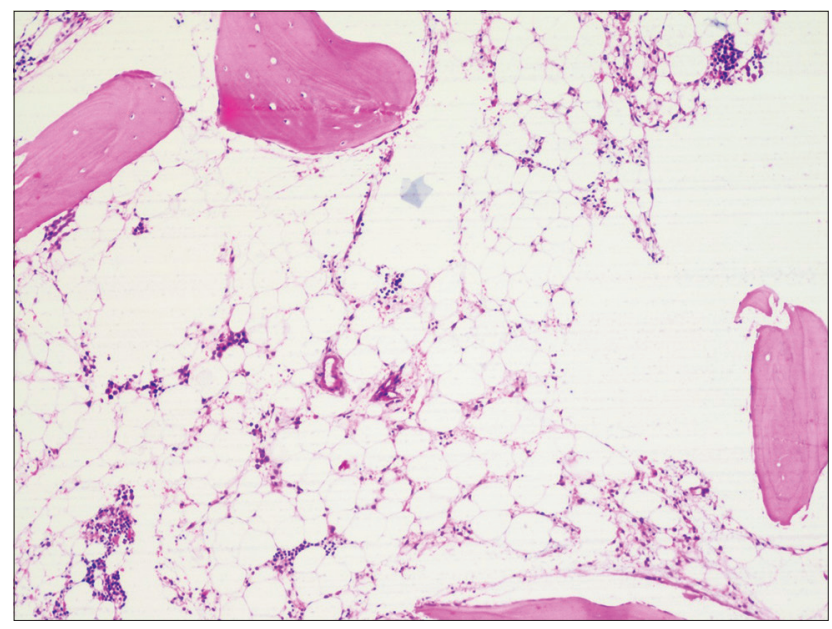

Figure 3: Bone marrow trephine showing fatty marrow $(\times 10)$
There are a 1000-fold increased risk of development of cutaneous malignancies, especially in those diagnosed under the age of 2 years and a 10-20-fold increased risk of developing noncutaneous malignancies. ${ }^{[9]}$

The commonly reported cutaneous malignancies include squamous cell carcinoma followed by melanoma and basal cell carcinoma.

Our patient had squamous cell carcinoma of the face.

In addition, the patient had pancytopenia which suggested the possibility of an infiltrative disorder of bone marrow. Bone marrow metastasis of malignant melanoma presenting as pancytopenia has already been reported in cases with XP. ${ }^{[10]}$ In our patient, bone marrow aspirate and trephine were consistent with aplastic anemia.

Review of the literature revealed that the common hematological disorders associated with XP are myelodysplastic syndrome and acute myeloid leukemia. ${ }^{[6]}$

Marrow aplasia in XP is very rare and has been reported so far in only a single case of XP. ${ }^{[7]}$ However, marrow

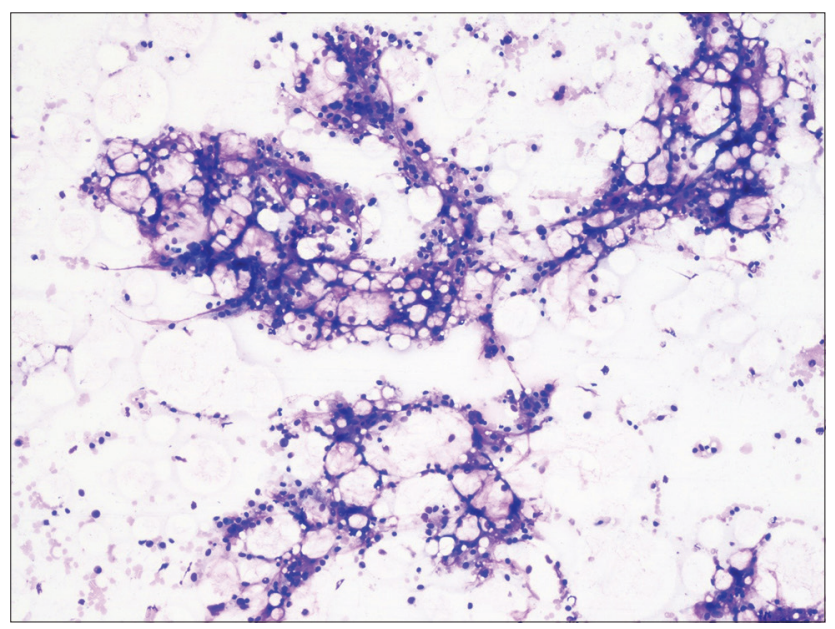

Figure 2: Bone marrow aspirate showing hypocellular marrow particles $(\times 10)$

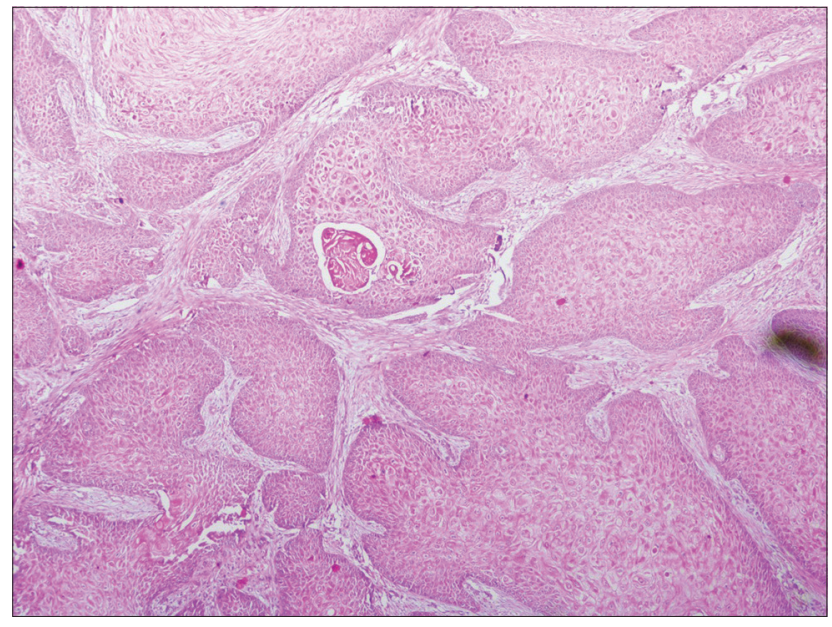

Figure 4: Biopsy showing squamous cell carcinoma $(\times 10)$ 
aplasia is quite common in other inherited DNA damage repair diseases such as Fanconi anemia. The patient did not have any features of Fanconi anemia. Even though skin hyperpigmentation has been reported in Fanconi anemia, it is not restricted to sun-exposed areas unlike in XP.

Aplastic anemia in children is generally attributed to drugs and viral infections. However, $90 \%$ of these cases are idiopathic in nature. ${ }^{[7]}$

The association of XP with leukemias and other internal malignancies shows that DNA damage repair mechanism is essential in repairing non-UV-mediated mutagenesis as well.

The association of aplastic anemia and XP as a new variant of this disease has not yet been proven. ${ }^{[7]}$ The clonal evolution of aplastic anemia to leukemia has been reported. ${ }^{[7]}$ Considering the foregoing discussion, it is tempting to suggest that this patient under reference can be considered to be at the increased risk of developing leukemia.

\section{Financial support and sponsorship}

Nil.

\section{Conflicts of interest}

There are no conflicts of interest.

\section{References}

1. Bilodi AK, Gangadhar MR. Xeroderma pigmentosa - A rare clinical entity. Indian J Med Case Rep 2013;2:21-4.

2. Feller L, Wood NH, Motswaledi MH, Khammissa RA, Meyer M, Lemmer J. Xeroderma pigmentosum: A case report and review of the literature. J Prev Med Hyg 2010;51:87-91.

3. Tamhankar PM, Iyer SV, Ravindran S, Gupta N, Kabra M, Nayak C, et al. Clinical profile and mutation analysis of xeroderma pigmentosum in Indian patients. Indian J Dermatol Venereol Leprol 2015;81:16-22.

4. Pandey A, Kuldeep K, Koul A, Tyagi M, Singh P, Sharma P, et al. Xeroderma pigmentosa with ocular association: Case report. Case Rep Clin Med 2013;2:466-9.

5. Lopes-Cardoso C, Paes da Silva Ramos Fernandes LM, Ferreira-Rocha J, Teixeira-Soares C, Antônio-Barreto J, Humberto-Damante J. Xeroderma pigmentosum - A case report with oral implications. J Clin Exp Dent 2012;4:e248-51.

6. Berbis P, Beylot C, Noe C, Doutre MS, Broustet A, Privat Y. Xeroderma pigmentosum and refractory anaemia in two first cousins. Br J Dermatol 1989;121:767-71.

7. Salob SP, Webb DK, Atherton DJ. A child with xeroderma pigmentosum and bone marrow failure. $\mathrm{Br} \mathrm{J}$ Dermatol 1992;126:372-4.

8. Chaudhary M, Jajoo SN, Agarwal R. Xeroderma pigmentosum: A case report of two siblings. J Immunodefic Disord 2012;1:2.

9. Rahman T, Sharma JD, Krishnatreya M, Kataki AC. Basaloid squamous carcinoma of skin associated with xeroderma pigmentosum in an 8-year-old child: A rare entity. Indian $\mathrm{J}$ Dermatol 2014;59:632.

10. Spiller SE, Hawkins DS, Finn LS, Sze RW, Sybert V. Metastatic malignant melanoma presenting as pancytopenia in a three-year-old boy. Pediatr Blood Cancer 2005;45:60-3. 